\title{
Protective Effects of Cysteine Analogues on Acute Myocardial Ischemia: Novel Modulators of Endogenous $\mathrm{H}_{2} \mathrm{~S}$ Production
}

\author{
Qian Wang, ${ }^{1}$ Xian-Li Wang,, Hong-Rui Liu, ${ }^{1}$ Peter Rose, ${ }^{2}$ and Yi-Zhun Zhu ${ }^{1}$
}

\begin{abstract}
The current study was designed to evaluate the pharmacologic effects of three novel cysteine-containing compounds: S-propyl-L-cysteine (SPC), S-allyl-L-cysteine (SAC), and S-propargyl-L-cysteine (SPRC) on $\mathrm{H}_{2} \mathrm{~S}$ production and antioxidant defenses in an acute myocardial infarction (MI) rat model. The enzymatic activities of superoxide dismutase (SOD), catalase (CAT), and glutathione peroxidase (GPx), as well as glutathione redox status and malonaldehyde (MDA) content, also were determined. All three compounds were found to preserve SOD and GPx activities and also tissue GSH levels while reducing the formation of the lipid peroxidation product MDA in ventricular tissues. With immunfluorescence assays, we observed the expression of CSE and Mn-SOD. The morphologic changes of the cardiac cells are seen with both light and electron microscopy. The corresponding pathologic alterations were characterized mainly as loss of adherence between cardiac myocytes and swollen or ruptured mitochondria at the ultrastructural level. Propargylglycine, a selective inhibitor of CSE, abolished the protective effects of each compound used in the current model. Our study provides novel evidence that SPC, SAC, and SPRC have cardioprotective effects in MI by reducing the deleterious effects of oxidative stress by modulating the endogenous levels of $\mathrm{H}_{2} \mathrm{~S}$ and preserving the activities of antioxidant defensive enzymes like SOD. Antioxid. Redox Signal. 12, 1155-1165.
\end{abstract}

\section{Introduction}

A CUTE MYOCARDIAL INFARCTION (MI) is one of the most serious health issues in both developed and developing countries (12). Therefore, pharmacologic strategies to reduce the mortality rate and to prevent MI are of great importance. One potential avenue of intervention is to target key cellular pathways known to function in the preservation of cardiac tissues and cells from the deleterious effects of oxidative stress. Interestingly, during the onset of MI, a decrease is observed in the expression levels and activities of antioxidant defensive enzymes such as superoxide dismutase (SOD), glutathione peroxidase (GPx), and catalase (CAT), as well as endogenous antioxidants like glutathione $(18,26)$. In contrast, oxidative stress increases. Elevated ROS levels and impaired antioxidant defenses are known to promote significant changes in membrane permeability, to disrupt membrane lipid bilayers, and to mediate functional modifications of cellular proteins that promote cardiac tissue damage. Therefore, the identification of pharmacologic agents that can prevent these changes is of biomedical importance.
Garlic (Allium satioum) has been prescribed for the treatment of several human diseases for centuries. Recent interest has focused on the role of garlic and its chemical constituents in the prevention of cardiovascular disease and cancer (14, 15). The mechanisms ascribed to garlic's biologic activities are believed to be partly due to its antioxidant action, although additional mechanisms also are likely to contribute (4). Recent work has shown that the cardioprotective effects of garlic may be attributed to its ability to modulate the endogenous levels of hydrogen sulfide $\left(\mathrm{H}_{2} \mathrm{~S}\right)$. Interestingly, $\mathrm{H}_{2} \mathrm{~S}$ was recently identified as a novel gaseous signaling molecule having a similar function to that of nitric oxide and carbon monoxide in the cardiovascular system of mammals $(1,25)$. Wei et al. (22) reported that $\mathrm{H}_{2} \mathrm{~S}$ acts as an antioxidant by attenuating oxidative stress in hypoxic pulmonary hypertension. Geng et al. (7) also proposed that $\mathrm{H}_{2} \mathrm{~S}$ protects the heart from isoproterenol-induced ischemic injury, at least in part by scavenging oxygen-free radicals and attenuating lipid peroxidation. Similarly, $\mathrm{H}_{2} \mathrm{~S}$ has been shown to protect primary rat cortical neurons from oxidative injury by stimulating the synthesis of the antioxidant glutathione (9). In the heart, $\mathrm{H}_{2} \mathrm{~S}$

\footnotetext{
${ }^{1}$ Department of Pharmacology, School of Pharmacy and Institute of Biomedical Sciences, Fudan University, Shanghai, China.

${ }^{2}$ Pharmaceutical Science Research Division, King's College, University of London, London, United Kingdom.
} 
is produced by the pyridoxal-5-phosphate-dependent enzyme, cystathionine- $\gamma$-lyase (CSE) with L-cysteine as a substrate. Interestingly, several chemical constituents have been characterized in extracts and preparations made from garlic that are structurally similar to cysteine, such as $S$-propyl-Lcysteine (SPC), S-propargyl-L-cysteine (SPRC), and S-allyl-Lcysteine (SAC). In the current study, we tested whether SPC, SAC, and SPRC also are used by mammalian metabolic pathways for the generation of the cardioprotective entity $\mathrm{H}_{2} \mathrm{~S}$ in vivo. In addition, we examined whether each compound was capable of preserving tissue antioxidant defensives in a rodent model of $\mathrm{MI}$.

\section{Materials and Methods}

All animal care and experimental protocols complied with the Animal Management Rules of local authorities and Care and Use of the Laboratory Animals of the Experimental Animal Center of Fudan University.

\section{Materials}

SAC (99\%) was supplied by Wakunaga Pharmaceutical Co. (Hiroshima, Japan); cysteine $(99.5 \%)$ was purchased from Hengbai Chemical Co. (Shanghai, China). Propyl bromide and propargyl bromide were purchased from Yancheng Kelida Chemical Co. (Zhejiang, China). PrimeScript 1st Strand cDNA Synthesis Kits were from TaKaRa (Dalian, China).

\section{Synthesis of SPC and SPRC}

SPC was synthesized from L-cysteine hydrochloride $(1.58 \mathrm{~g}, 0.01 \mathrm{~mol})$ and propyl bromide $(1.29 \mathrm{~g}, 0.01 \mathrm{~mol})$. The desired product was then precipitated on acidification with acetic acid. SPRC (also named as ZYZ-802) was synthesized from the reaction of $\mathrm{L}$-cysteine with propargyl bromide and purified by recrystallization from an ethanol-water mixture (96.1\%). The final product was verified with ${ }^{1} \mathrm{H}$ nuclear magnetic resonance spectroscopy. The structures of each respective cysteine analogue used in the current study are shown in Fig. 1.

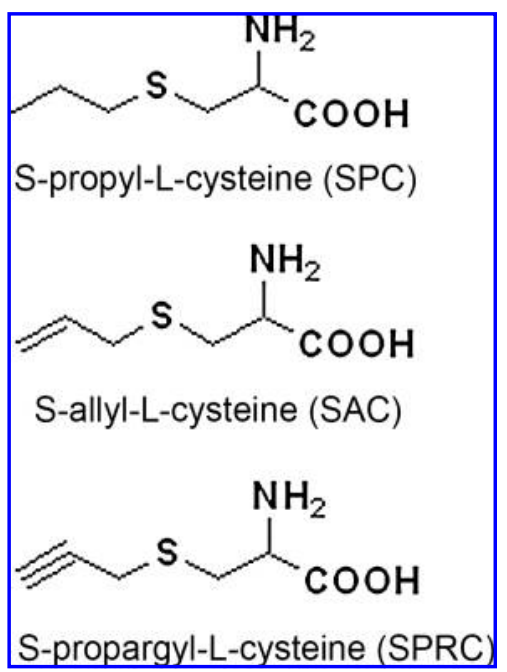

FIG. 1. The chemical structures of SPC, SAC, and SPRC.

\section{Treatment protocols}

Adult male Sprague-Dawley rats (200 to 250 g) were randomly assigned into five treatment groups: sham vehicle (saline) $(n=6)$, MI treated with vehicle $(n=10)$, MI treated with SPC $(50 \mathrm{mg} / \mathrm{kg} /$ day) $(n=10)$, MI treated with SAC $(50 \mathrm{mg} / \mathrm{kg} /$ day) $(n=10)$, and MI treated with SPRC (50 mg/ $\mathrm{kg} /$ day) $(n=10)$. In addition, five separate groups $(n=6)$ representing each treatment group as described earlier were treated with the cystathionine- $\gamma$-lyase (CSE) inhibitor, propargylglycine (PAG, $10 \mathrm{mg} / \mathrm{kg} /$ day).

\section{Experimental induction of acute myocardial infarction}

Rats were injected intraperitoneally on a daily basis for 7 days before occlusion of the coronary artery to induce MI. The MI model was induced on day 7 by ligating the coronary artery, as previously described (27). After the surgery, all treatment regimens were continued for an additional 2 days until the animals were killed $48 \mathrm{~h}$ after surgery. Hearts were also excised, washed in ice-cold saline, and stored at $-80^{\circ} \mathrm{C}$ for subsequent experimental assays.

\section{Glutathione levels and antioxidant enzyme analysis}

Oxidized glutathione (GSSG) and reduced glutathione (GSH) levels were measured by using a commercially available kit according to the manufacturer's instructions (Beytime Institute of Biotechnology, Nantong, China). For the determination of antioxidant enzyme activities, $0.05 \mathrm{~g}$ LV tissues were homogenized in $50 \mathrm{mM}$ ice-cold potassium phosphate buffer ( $\mathrm{pH}$ 6.8). Superoxide dismutase (SOD) activity was measured as described by Dieterich et al. (6). In brief, total SOD activity was determined by monitoring the inhibition of pyrogallol autooxidation at $420 \mathrm{~nm}$. To measure Mn-SOD activity, $\mathrm{Cu}$ Zn-SOD was inhibited by using diethyldithiocarbamic acid. SOD activity is expressed as units per milligram protein, where $1 \mathrm{U}$ is the amount required to inhibit pyrogallol oxidation by $50 \%$. GPx and catalase (CAT) activities were determined by the modified method of Alvarez (2). Lipid peroxidation was measured in terms of tissue MDA contents by using the thiobarbituric acid (TBA) assay, with 1,1,3,3-tetramethoxypropane as an external standard for the construction of standard curves. MDA levels are expressed as nanomoles MDA per milligram protein (24). Protein content was determined by using a BCA protein assay kit (Beytime Institute of Biotechnology).

\section{Measurement of CSE activity}

CSE activity was assayed as described (26). In brief, $0.1 \mathrm{~g}$ of left ventricular myocardial tissue was thawed on ice and homogenized in $2 \mathrm{ml}$ of $100 \mathrm{mM}$ ice-cold potassium phosphate buffer ( $\mathrm{pH} 7.4$ ). Tissue homogenates were centrifuged at $24,000 \mathrm{~g}$ for $5 \mathrm{~min}$ at $4^{\circ} \mathrm{C}$, and the supernatant was used for the assay. The reaction mixture contained $20 \mu \mathrm{l}$ of $10 \mathrm{mM} \mathrm{L-}$ cysteine, $20 \mu \mathrm{l}$ of $2 \mathrm{mM}$ pyridoxal-5-phosphate, $30 \mu \mathrm{l}$ of saline, and $430 \mu \mathrm{l}$ tissue homogenate. The catalytic reaction was initiated by transferring the reaction mixture contained in microtubes from ice to a $37^{\circ} \mathrm{C}$ water bath for $30 \mathrm{~min}$. Then $250 \mu \mathrm{l}$ of $1 \%$ zinc acetate was added to the tubes by using a syringe to trap any evolved $\mathrm{H}_{2} \mathrm{~S}$. Then $250 \mu \mathrm{l}$ of $10 \%$ trichloroacetic acid (TCA) was added to quench the enzymatic reaction. Finally, $133 \mu \mathrm{l} N, N$-dimethyl- $p$-phenylenediamine sulfate (NNDPD) 
in $7.2 \mathrm{M} \mathrm{HCl}$ and $133 \mu \mathrm{l}$ of $\mathrm{FeCl}_{3}$ in $1.2 \mathrm{M} \mathrm{HCl}$ were added. The absorbance of the final reaction mixture was measured at $670 \mathrm{~nm}$ by using a 96-well microplate reader (Tecan Systems Inc., Oberdiessbach, Switzerland). All samples were assayed in duplicate, and the $\mathrm{H}_{2} \mathrm{~S}$ concentrations for each sample were calculated against a calibration curve made by using NaHS (3.125 to $250 \mu \mathrm{M})$. Results are expressed as micromoles per gram of protein per hour. Protein content was determined by using a BCA assay kit (Beytime).

\section{Real-time PCR assay}

Total RNA from either the left ventricle ( $n=4$ each group) or cultured cardiomyocytes was isolated by using Trizol reagent (Invitrogen, Carlsbad, CA). RNA was quantified spectrophotometrically by measuring the optical density of samples at $260 / 280 \mathrm{~nm}$. Two micrograms of RNA were reverse-transcribed to cDNA with the PrimeScript 1st Strand cDNA Synthesis Kit (TaKaRa). Gene expression was performed by using real-time PCR with the SYBR Green PCR Master Mix (Bio-Rad) on a BIO-RAD IQ5 system. Expressions of SOD1, SOD2, CSE, GPx, and CAT mRNA were determined. Results were normalized to $\beta$-actin. Three duplicates were performed. The primers used for real-time PCR are shown in Table 1.

\section{Western blot analysis}

Frozen tissues ( $n=4$ per group) were cut into small pieces, homogenized in $0.5 \mathrm{ml}$ of RIPA buffer $(150 \mathrm{mM} \mathrm{NaCl}, 1 \%$ NP-40, $0.5 \%$ deoxycholate, $0.1 \%$ sodium dodecylsulfate, $50 \mathrm{mM}$ Tris-hydrochloric acid, $2 \mathrm{mM}$ phenylmethylsulfonyl fluoride, $\mathrm{pH} 7.4$ ), and incubated at $4{ }^{\circ} \mathrm{C}$ overnight. The dissolved proteins were collected after centrifugation at $10,000 \mathrm{~g}$ for $30 \mathrm{~min}$, and the supernatant was then collected. Protein concentrations were determined by using the enhanced BCA protein assay kit (Beytime Biotechnology). To detect CSE, $\mathrm{CuZn-SOD}$, and Mn-SOD protein expression levels, cell lysates were subjected to SDS-PAGE analysis on a $12 \%$ (wt/vol) acrylamide gel and then electrotransferred onto a PVDF membrane (Millipore Corporation). Membranes were then incubated with the appropriate secondary horseradish peroxidase-conjugated anti-rabbit IgG antibodies at a 1:10,000 dilution (Jackson ImmunoResearch Laboratories Inc., West

Table 1. Primer Sequence of Six Genes USED FOR REAL-TIME PCR

\begin{tabular}{ll}
$\begin{array}{c}\text { Gene } \\
\text { name }\end{array}$ & \multicolumn{1}{c}{\begin{tabular}{c}
\multicolumn{1}{c}{ Primer sequence } \\
SOD1
\end{tabular}} \\
& $\begin{array}{l}\text { Forward: 5'-TGCAGGGCGTCATTCACTTC-3' } \\
\text { Reverse: 5'-ACCCATGCTCGCCTTCAGTT-3' }\end{array}$ \\
SOD2 & $\begin{array}{l}\text { Forward: 5'-TTGCCGCCTGCTCTAATCAG-3' } \\
\text { Reverse: 5'-GTAAGCGTGCTCCCACACATC-3' }\end{array}$ \\
CSE & $\begin{array}{l}\text { Forward: 5'-GAGGGAAGTCTTGGAAATGGC-3' } \\
\text { Reverse: 5'-CGCAACATTTCATTTCCCG-3' }\end{array}$ \\
GPx & $\begin{array}{l}\text { Forward: 5'-GCGAGGTGAATGGTGAGAAGG-3' } \\
\text { Reverse: 5'-GCATTCCGCAGGAAGGTAAA-3' }\end{array}$ \\
CAT & $\begin{array}{l}\text { Forward: 5'-ACTCAGGTGCGGACATTCTATACG-3' } \\
\text { Reverse: 5'-AGCATCTTTCAGGTGGTTGGC-3' }\end{array}$ \\
$\beta-$ & $\begin{array}{l}\text { Forward: 5'-TTCAACGGCACAGTCAAGG-3' } \\
\text { Actin }\end{array}$ \\
\hline
\end{tabular}

Grove, PA). Immunoreactive proteins were visualized by using the ECL Western blotting detection kit (Alpha Innotech, San Leandro, CA).

\section{Histologic analysis and immunofluorescence assays}

Heart tissues $(2 \mathrm{~mm})$ were embedded in OCT medium immediately. Frozen sections $(6 \mu \mathrm{m}$ thick) were used for hematoxylin-eosin staining and immunofluorescence assays.

By using antibodies for CSE and Mn-SOD, we performed immunofluorescence assays to measure the relation with the endogenous $\mathrm{H}_{2} \mathrm{~S}$ production and the expression of the antioxidant enzyme Mn-SOD. For immunofluorescence assays, sections were washed $(0.1 \mathrm{M}$ Tris, $\mathrm{pH} 7.6,15 \mathrm{~min})$, denatured $\left(2 \mathrm{~N} \mathrm{HCl}, 37^{\circ} \mathrm{C}, 30 \mathrm{~min}\right)$, rinsed $(0.1 \mathrm{M} \mathrm{PBS}, 10 \mathrm{~min})$, incubated with $1 \% \mathrm{H}_{2} \mathrm{O}_{2}$ in $0.1 \mathrm{M}$ Tris for $30 \mathrm{~min}$, rinsed, blocked $(10 \%$ normal goat serum, $\left.37^{\circ} \mathrm{C}, 30 \mathrm{~min}\right)$, and incubated with antiCSE antibody and anti-MnSOD antibody ( $4^{\circ} \mathrm{C}$ overnight). Sections were rinsed (0.1 M PBS, $10 \mathrm{~min})$, incubated with tetraethyl rhodamine isothiocyanate (TRITC)-conjugated goat anti-rabbit IgG and fluorescein isothiocyanate (FITC)conjugated anti-mouse IgM (room temperature, $2 \mathrm{~h}$ ), and rinsed, mounted, dried, and coverslipped by using DAPI.

\section{Light-microscopy and electron-microscopy observation}

For transmission electron microscopic study, specimens were prefixed in $2.5 \%$ glutaraldehyde solution, diced into $1 \mathrm{~mm}^{3}$, followed by three 15-min rinses with $0.1 \mathrm{M}$ phosphate buffer (pH7.4). Postfixation was in cold $1 \%$ aqueous osmium tetroxide for $1 \mathrm{~h}$. After a rinse with phosphate buffer again, the specimens were dehydrated in a graded ethanol series of 50 to $100 \%$ and then embedded in Epon 812. Ultra-thin sections were sliced with glass knives on a LKB-V ultramicrotome (Nova, Trelleborg, Sweden), stained with uranyl acetate and lead citrate, and examined under a Hitachi H-600 electron microscope.

\section{Statistical analysis}

All values are presented as mean and standard deviations. One-way analysis of variance (ANOVA) was used to examine statistical comparisons between groups. The statistical significance of differences between two groups was determined by using a two-tailed Student's $t$ test. A $\chi^{2}$ (chi-square) test was used for calculating the significance of the mortality data. A probability value of $<0.05$ was taken to indicate statistical significance. All analyses were performed by using SPSS 12.0.

\section{Results \\ GSH and GSSG levels}

The GSH content of left ventricular tissues of rats in the MI vehicle group were lower than those of the sham group $(9.5 \pm 0.7 \mu \mathrm{M} / \mathrm{mg}$ protein vs. $24.3 \pm 1.6 \mu \mathrm{M} / \mathrm{mg}$ protein, $p<0.01)$. In rats treated with the three cysteine derivatives, GSH levels were preserved. In the SPC-, SAC-, and SPRCtreated animals, GSH levels were increased by $67 \%, 77 \%$, and $80 \%$, as compared with the MI vehicle group $(p<0.05)$. Interestingly, in the MI + PAG group, the GSH level was reduced to $7.8 \pm 0.7 \mu \mathrm{M} / \mathrm{mg}$ protein. PAG also was found to abolish the observed increases in GSH levels in the SPC-, SAC-, and SPRC-treated groups (Fig. 2A). In addition, GSSG 

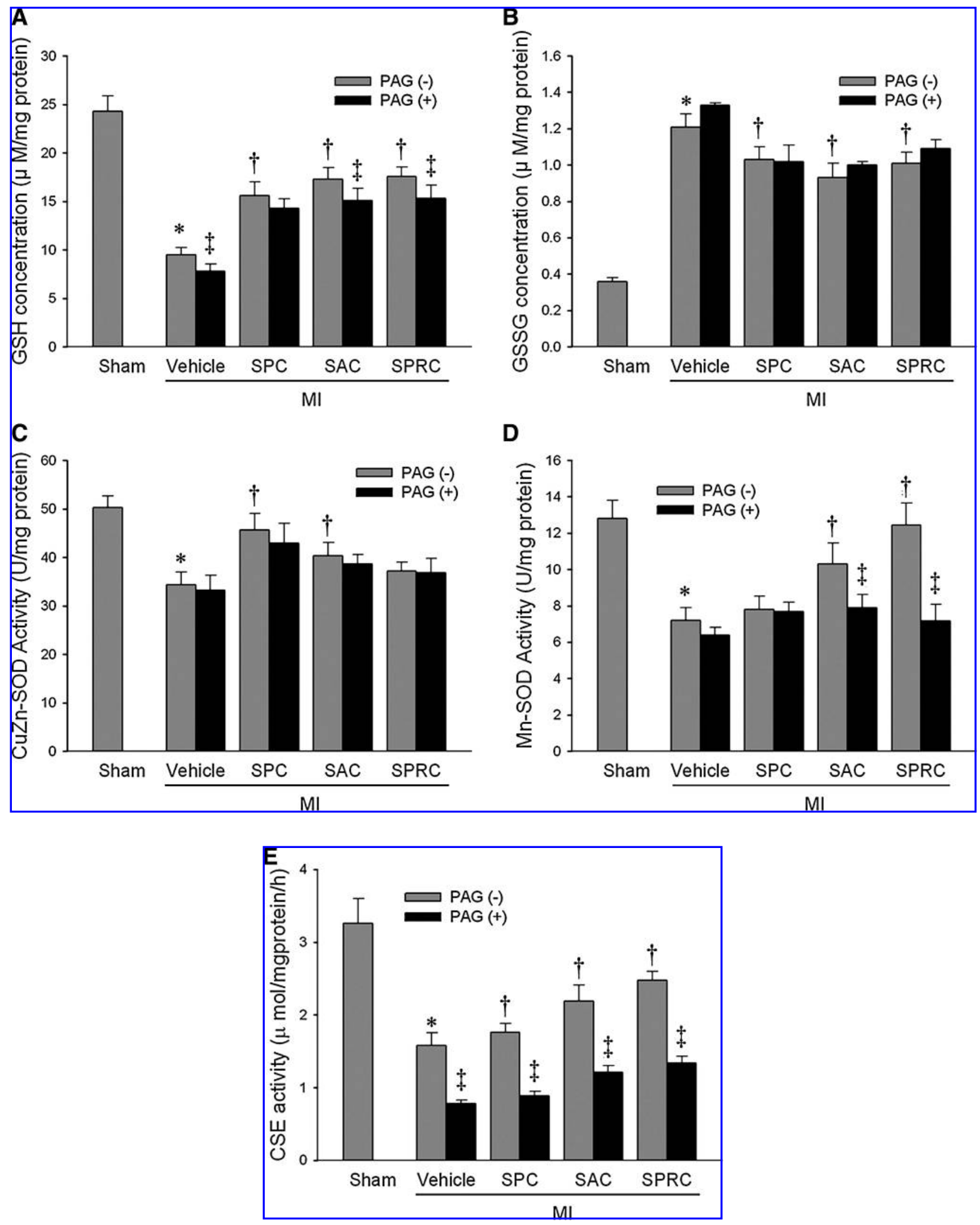

FIG. 2. SPC, SAC, and SPRC modulate antioxidant defenses in rats. (A) Tissue GSH levels. (B) Tissue GSSG concentrations. (C) CuZn-SOD activity. (D) Mn-SOD activity. (E) CSE activity in the left ventricular tissues in all MI and sham-operated rats. In (A-D), $n=6$ for each group; in (E), $n=4$ for each group. ${ }^{*} p<0.05$ when compared with the sham group. ${ }^{\dagger} p<0.05$ as compared with the MI vehicle group. ${ }^{\star} p<0.05$ comparing PAG (-) pretreatment groups. 
Table 2. GPx and CAT Activities and MDA Concentrations in Left Ventricular Tissues as Determined in Each Study Group

\begin{tabular}{lccc}
\hline & GPx $(\mu \mathrm{mol} / \mathrm{min} / \mathrm{mg}$ protein $)$ & CAT $(\mathrm{U} / \mathrm{mg}$ protein) & MDA (nmol/mg protein) \\
\hline Sham & $3.45 \pm 0.23$ & $9.92 \pm 0.71$ & $1.29 \pm 0.15$ \\
MI + vehicle & $3.03 \pm 0.31^{\mathrm{a}}$ & $6.64 \pm 0.52^{\mathrm{a}}$ & $2.47 \pm 0.14^{\mathrm{a}}$ \\
MI+PAG & $3.00 \pm 0.24$ & $6.44 \pm 0.41$ & $2.61 \pm 0.12^{\mathrm{c}}$ \\
MI+SPC & $3.36 \pm 0.21^{\mathrm{b}}$ & $7.28 \pm 0.69$ & $1.83 \pm 0.16^{\mathrm{b}}$ \\
MI+SPC+PAG & $3.32 \pm 0.33$ & $7.25 \pm 0.52$ & $2.02 \pm 0.12$ \\
MI+SAC & $3.37 \pm 0.42$ & $7.36 \pm 0.70$ & $1.62 \pm 0.18^{\mathrm{b}}$ \\
MI+SAC+PAG & $3.49 \pm 0.30$ & $6.92 \pm 0.94$ & $1.98 \pm 0.09^{\mathrm{c}}$ \\
MI+SPRC & $3.54 \pm 0.26^{\mathrm{b}}$ & $7.47 \pm 0.64$ & $1.56 \pm 0.10^{\mathrm{b}}$ \\
MI+SPRC+PAG & $3.47 \pm 0.23$ & $7.01 \pm 0.77$ & $1.98 \pm 0.17^{\mathrm{c}}$ \\
\hline
\end{tabular}

Data are shown as mean values $\pm \mathrm{SD}$ of five animals per group.

${ }^{\mathrm{a}} p<0.05$ when compared with the sham group.

${ }^{\mathrm{b}} p<0.05$ when compared with the MI group.

${ }^{c} p<0.05$ when compared with the PAG (-) group.

levels in the MI vehicle rats were higher than those in the sham-treated animals $(p<0.05)$, and all three cysteine analogues tested in the current study were found to decrease GSSG levels in MI animals $(p<0.05)$. The decrease in GSSG levels in the cysteine analogues-treated animals is suggestive of a reduction in oxidative stress.

\section{Antioxidant enzyme activities and MDA formation in $\mathrm{Ml}$ tissues}

The activities of tissue antioxidant enzymes are shown in Table 2. In our study, all three cysteine derivatives were found to increase the enzymatic activities of GPx as compared with the MI vehicle group. Similarly, the free radical-scavenging enzymes $\mathrm{CuZn-SOD}$ and Mn-SOD also were preserved. In the SPC group, CuZn-SOD activity was increased to $45.7 \pm$ $3.4 \mathrm{U} / \mathrm{mg}$ protein, as compared with the MI vehicle group of $34.4 \pm 2.6 \mathrm{U} / \mathrm{mg}$ protein (Fig. 2C). However, no noticeable changes were observed for Mn-SOD. In contrast, SAC increased both the $\mathrm{Cu}-\mathrm{Zn}$ SOD activity to $40.3 \pm 2.8 \mathrm{U} / \mathrm{mg}$ protein and the Mn-SOD activity to $10.32 \pm 1.12 \mathrm{U} / \mathrm{mg}$ protein as compared with the MI vehicle group of $34.4 \pm 2.6$ and $7.21 \pm 0.68 \mathrm{U} / \mathrm{mg}$ protein, respectively $(p<0.05)$. Interestingly, in the SPRC-treated group, only Mn-SOD was induced to $12.45 \pm 1.20 \mathrm{U} / \mathrm{mg}$ protein and was significantly different from the MI vehicle group ( $p<0.01$; Fig. 2D).
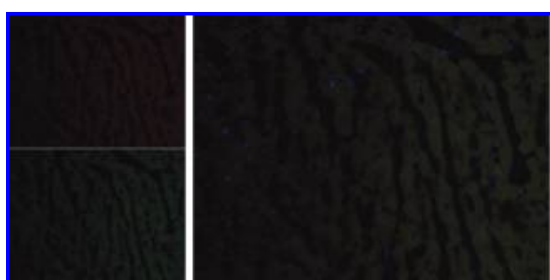

Sham
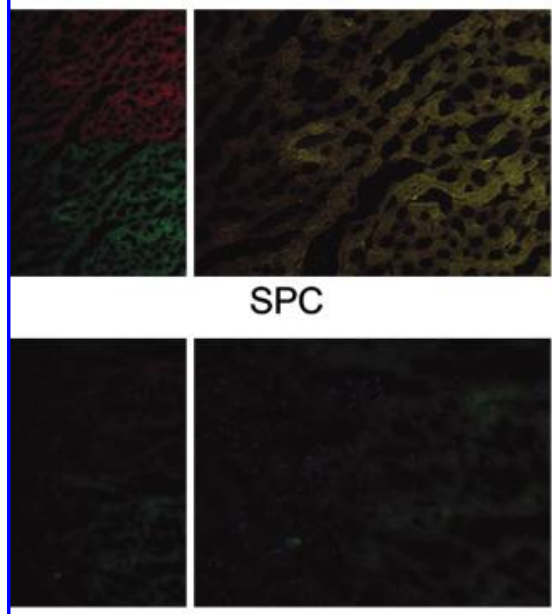

SPC

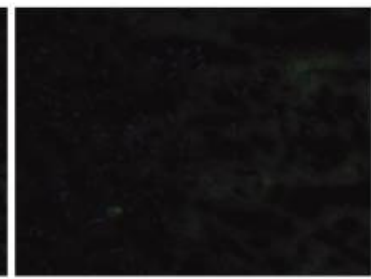

$S P C+P A G$
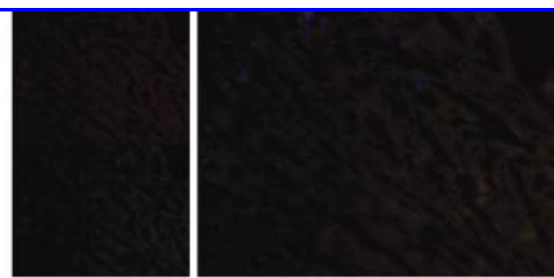

vehicle
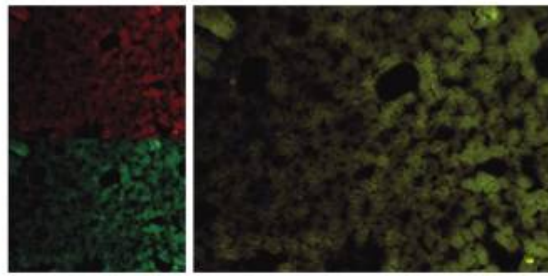

SAC
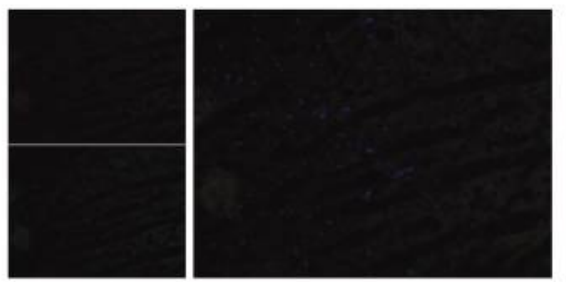

SAC+PAG
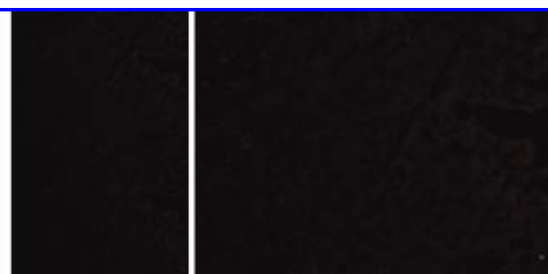

PAG
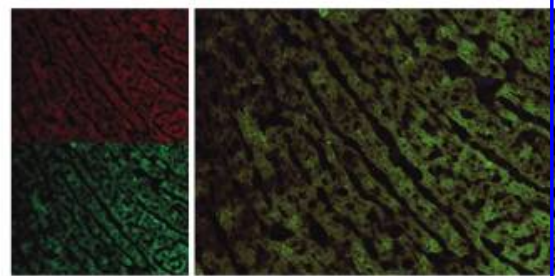

SPRC
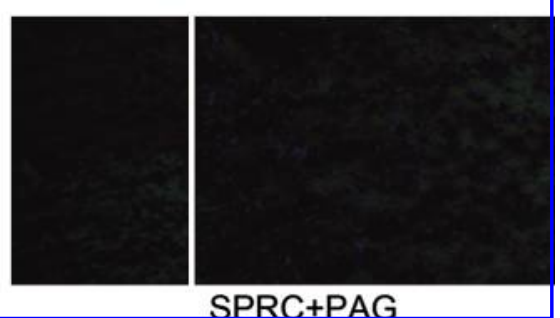

FIG. 3. Immunofluorescence assay of CSE and Mn-SOD expression $(\times 400)$. CSE protein appears red, and Mn-SOD protein appears green. Myocardial chromatin was stained by using DAPI to show the location of nuclei and is shown in blue. (For interpretation of the references to color in this figure legend, the reader is referred to the web version of this article at www.liebertonline.com/ars). 

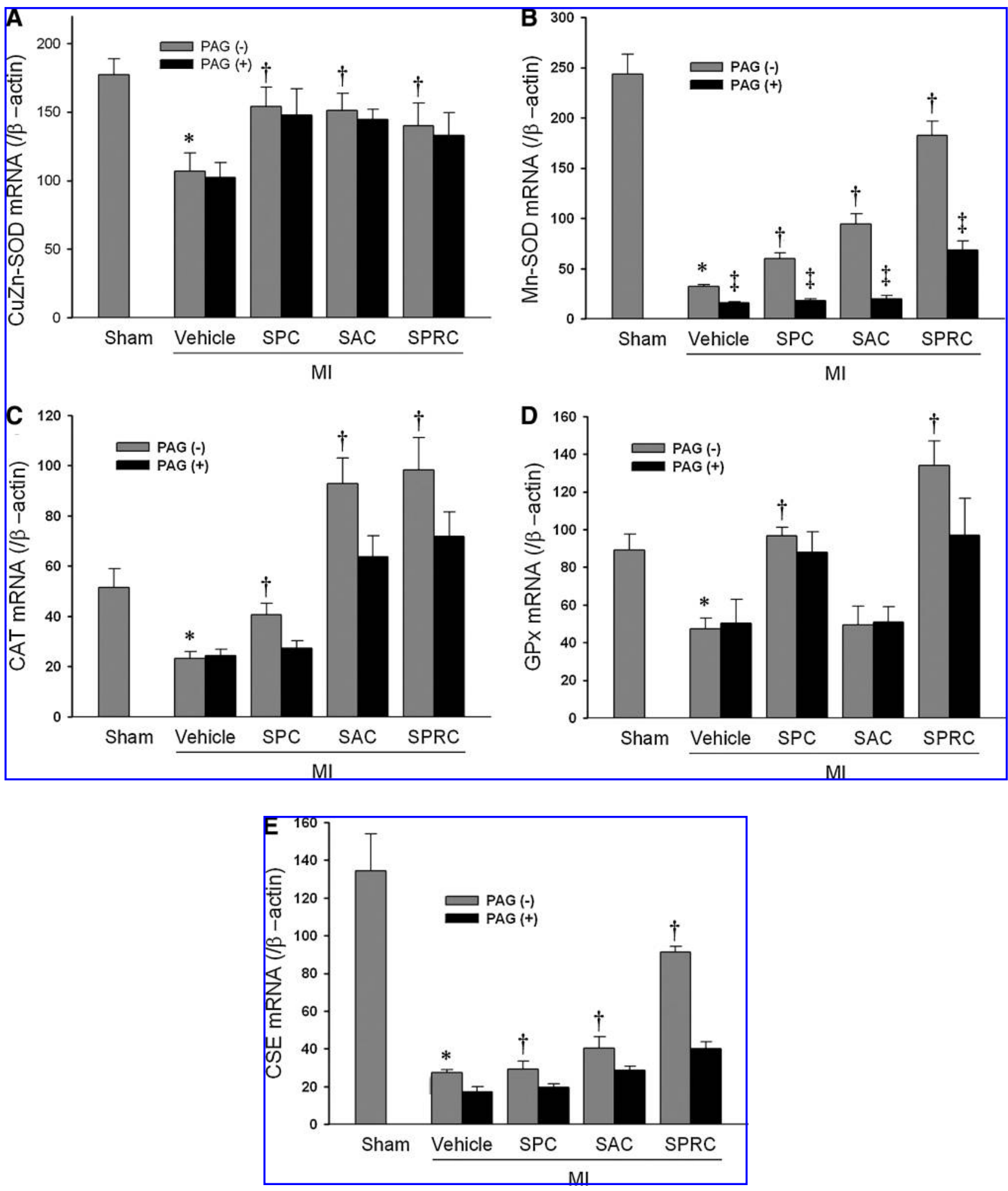

FIG. 4. mRNA expression levels of antioxidant defensive enzymes in heart tissues of rats exposed to SPC, SAC, and SPRC. (A) CuZn-SOD. (B) Mn-SOD. (C) CAT. (D) GPx. (E) CSE expression in all MI and sham-operated rats; $n=4$ for each group. ${ }^{*} p<0.05$ when compared with the sham group. ${ }^{\dagger} p<0.05$ as compared with the MI vehicle group. ${ }^{\star} p<0.05$ compared with the PAG (-) pretreatment groups.

In the PAG-treatment groups, Mn-SOD activity was significantly decreased to $7.68 \pm 0.52 \mathrm{U} / \mathrm{mg}$ protein (SPC $+\mathrm{PAG}$ ), $7.89 \pm 0.73 \mathrm{U} / \mathrm{mg}$ protein $(\mathrm{SAC}+\mathrm{PAG})$, and $7.18 \pm 0.9 \mathrm{U} / \mathrm{mg}$ protein in the SPRC + PAG group $(p<0.05)$. No significant changes in CuZn-SOD activity were observed for any of the cysteine analogues treated with PAG.

As summarized in Table 2, the antioxidant enzyme activities of GPx and CAT in left ventricular homogenates were 

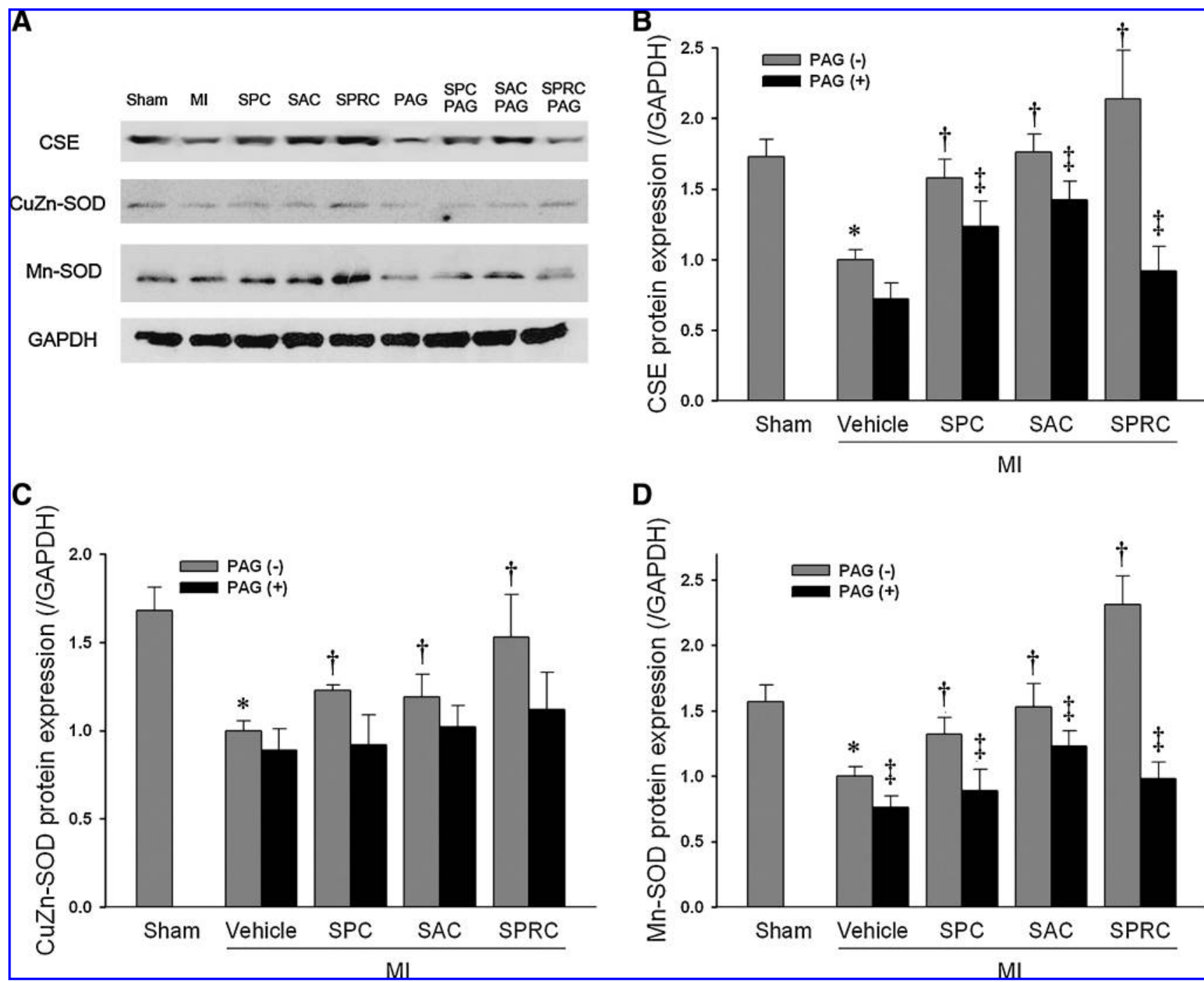

D

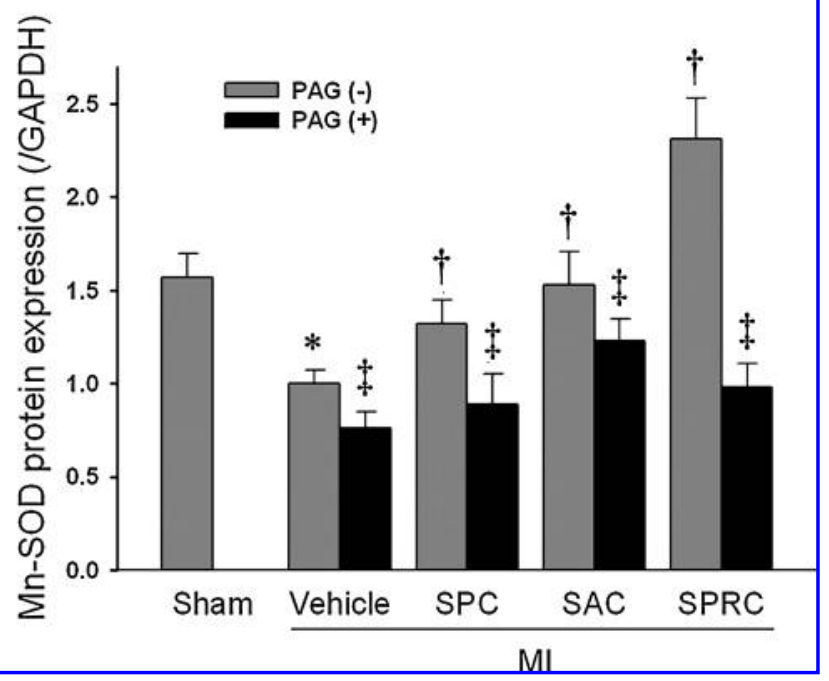

FIG. 5. Western blotting analysis of the relative protein contents of (A) protein bot of CSE, CuZn-SOD and Mn-SOD, (B) CSE protein, (C) CuZn-SOD protein, and (D) Mn-SOD protein in all MI and sham-operated rats, $n=4$ for each group. ${ }^{*} p<0.05$ when compared with the sham group. ${ }^{\dagger} p<0.05$ as compared with the MI vehicle group. ${ }^{*} p<0.05$ comparing PAG $(-)$ pretreatment groups.

increased in the SPC- and SPRC-treated groups but not in the SAC group. To support these findings, we determined the tissue levels of MDA, an additional biomarker of oxidative stress. In this study, MDA levels also were found to be increased in the MI vehicle group as compared with the sham group $(p<0.01)$. However, treatment with SPC, SAC, and SPRC reduced MDA levels.

\section{Left ventricular CSE activity in rats after MI injury}

Left ventricular CSE activity was analyzed in the tissue homogenates from all treatment groups $(n=4)$. SPC, SAC, and SPRC increased CSE activity by 1.1-fold, 1.4-fold, and 1.6fold, respectively, as compared with the MI vehicle group $(1.76 \pm 0.12 \mu \mathrm{mol} / \mathrm{g}$ protein $/ \mathrm{h}, 2.19 \pm 0.22 \mu \mathrm{mol} / \mathrm{g}$ protein $/ \mathrm{h}$, and $2.48 \pm 0.12 \mu \mathrm{mol} / \mathrm{g}$ protein $/ \mathrm{h}$ vs. $1.58 \pm 0.17 \mu \mathrm{mol} / \mathrm{g}$ protein $/ \mathrm{h} ; p<0.01$ ) (Fig. 2E). SPRC-treated animals had the highest CSE activity of all three of the cysteine derivatives tested. The PAG-treated group had the lowest CSE activity of $0.78 \pm 0.05 \mu \mathrm{mol} / \mathrm{g}$ protein $/ \mathrm{h}$. In the SPC + PAG $(0.89 \pm$
$0.06 \mu \mathrm{mol} / \mathrm{g}$ protein $/ \mathrm{h}), \quad$ SAC + PAG $^{-} \quad(1.21 \pm 0.09 \mu \mathrm{mol} / \mathrm{g}$ protein $/ \mathrm{h})$, and SPRC + PAG $(1.34 \pm 0.09 \mu \mathrm{mol} / \mathrm{g}$ protein $/ \mathrm{h})$ treated groups, the CSE activities were significantly lower as compared with those in the SPC-, SAC-, and SPRC-treated groups alone $(p<0.05)$ (Fig. $2 \mathrm{E})$.

\section{Immunohistochemical analysis of CSE and Mn-SOD contents in heart tissues of rats}

As shown in Fig. 3, the CSE protein is stained red, and MnSOD protein is stained green. Myocardial nuclei are shown in blue after staining with DAPI. The CSE protein content of the MI vehicle group and PAG-intervened groups was lower than that in the SPC, SAC, and SPRC groups. Similar findings also were found for the tissue levels for the antioxidant defensive enzyme, Mn-SOD.

\section{Oxidative enzyme and CSE mRNA expression}

SPC, SAC, and SPRC increased CuZn-SOD expression as compared with the MI vehicle group (1.44-fold, 1.42-fold, 


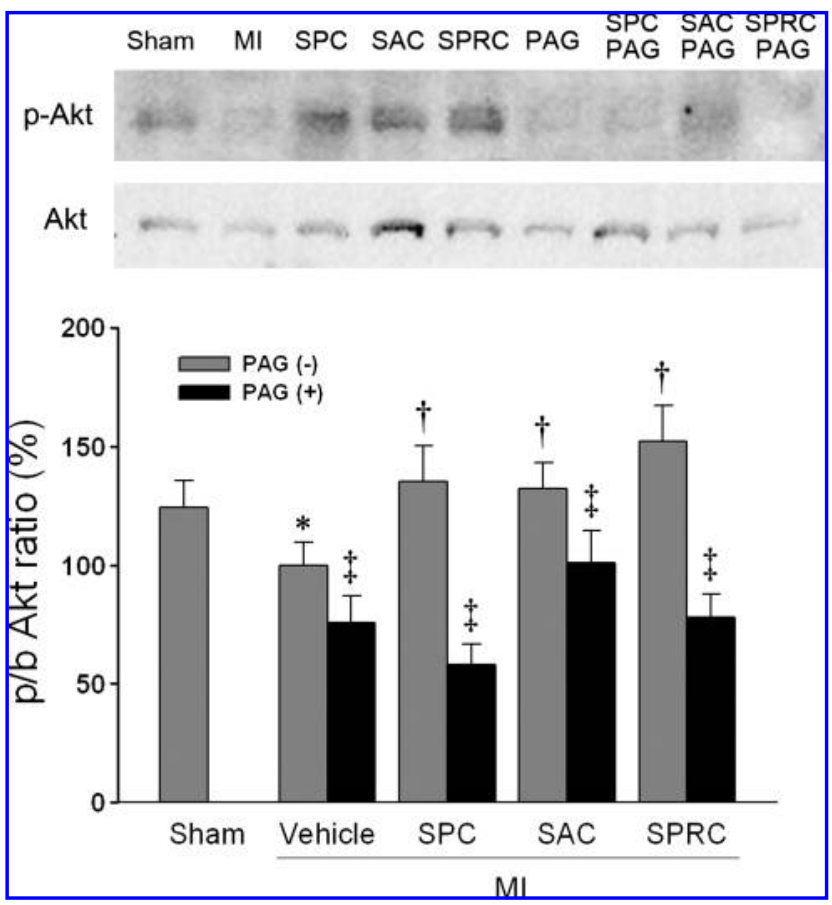

FIG. 6. Akt content and phosphorylation status in MI rats treated with SPC, SAC, and SPRC, $n=4$ for each group. ${ }^{*} p<0.05$ when compared with the sham group. ${ }^{\dagger} p<0.05$ as compared with the MI vehicle group. ${ }^{*} p<0.05$ compared with PAG (-) pretreatment groups.

and 1.31-fold of the MI vehicle group; $p<0.05$; Fig. 4A). No significant changes were found between the cysteine analogues-treated groups with PAG and without PAG in CuZn-SOD mRNA expression.

The mRNA ratios of $\mathrm{Mn}$-SOD/ $\beta$-actin were increased in SPC-, SAC-, and SPRC-treated groups (1.81-fold, 2.93-fold, and 5.7-fold of the MI vehicle group, respectively; $p<0.05$; Fig. 4B). After PAG was added, the groups also had a lower Mn-SOD mRNA expression.

Similar changes in the expression of CSE mRNA were found in MI rats that were treated with SPC, SAC, and SPRC (1.1-fold, 1.5-fold, and 3.3-fold vs. MI vehicle rats; $p<0.01$ ). PAG inhibited mRNA expression of CSE by 0.63 -fold versus MI vehicle $(p<0.01)$. In the SPC + PAG-, SAC + PAG-, and SPRC + PAG-treated groups CSE mRNA expression was significantly reduced (0.66-fold, 0.7 -fold, and 0.43 -fold $v$ s. SPC, SAC, and SPRC; $p<0.05$ ) (Fig. $4 \mathrm{~A}$ and C).

\section{Western blotting}

For all groups, the MI vehicle-treated rats had significantly lower CSE protein and mRNA expression as compared with the sham group. The SPC-, SAC-, and SPRC-treated groups showed a significant increase in CSE protein expression when compared with the MI vehicle group (1.57-fold, 1.76, and 2.14fold vs. MI vehicle group; $p<0.05)$. Furthermore, SPC-, SAC-, and SPRC-treated groups were found to have a significant upregulation of CuZn-SOD and Mn-SOD protein. In contrast, PAG-only abolished the increase Mn-SOD protein expression comparing those without PAG pretreatment groups, respectively ( $p<0.05$; Fig. 5A, C, and D). We also determined the relative expression levels of the serine/threonine kinase Akt.
SPC, SAC, and SPRC increased the phosphor-Akt/total Akt as compared with the MI vehicle group (1.41-fold, 1.36-fold, and 1.52-fold vs. the MI vehicle group; $p<0.05$; Fig. 6). However, PAG inhibited the increase in phosphor-Akt/total Akt induced by three cysteine analogues.

\section{Pathologic observations}

Figures 7 and 8 present MI-induced pathologic changes in rat myocardium. The architecture of the myocardium was intact with regular myofiber arrangement in the sham-group rats. In hearts of rats treated with MI, disorganizations of cell structure and loss of adherence between cardiomyocytes were pronounced. The myocardial damage included enlarged cells with enlarged and often bizarre-shaped nuclei, occasional cytoplasmic vacuolization and partial degenerative muscle fibers. At the PAG-treated group, disarray of myocardial fibers and the degenerative muscle fibers with myocytolysis were the most prominent features. Cardiac ultrastructure was normal with intact and abundant mitochondria in hearts of the sham rats, whereas most mitochondria were seriously swelling in the hearts of rats operated on with MI. Moreover, the swelling of interstices among mitochondria and some mitochondria with ruptured outer membrane were observed as well. The SPC group showed a bubble in the nuclei, but the structure of mitochondria looked more normal than those MI vehicle group. The pathologic morphology of cardiac cells in SPRC group was almost same as that in the sham group, and the SAC-treated group were better than the MI group, especially in mitochondrial structure.

\section{Discussion}

Garlic (Allium sativum) is believed to be useful for disease prevention. The beneficial effects of garlic have been ascribed to its potent antioxidant action (16). SAC is one of the major organosulfur compounds found in aged garlic extracts, and the allyl moiety appears to be crucial for any biologic activity. Similarly, SPC has been identified in extracts prepared from Allium species such as garlic and onion $(10,19)$. Several studies have indicated that SAC and SPC can inhibit TG and cholesterol biosynthesis in cultured rat hepatocytes $(8,11)$. SPRC, a chemical species containing a propargyl structure, also was reported to have anticholesterolemic activity (13). We recently showed that SPRC and SAC have cardioprotective effects in MI by reducing the mortality rate as well as by reducing the infarct size in rats, and we proposed a role for the $\mathrm{H}_{2} \mathrm{~S}$-associated pathway in mediating this protection (21). In this article, the infarct size/total area of the myocardium also was significantly reduced in rats subjected to SPC treatment, as compared with the MI vehicle rats by $26.1 \pm 1.6 \%$ vs. $36.2 \pm 1.3 \%$, respectively $(p<0.05)$.

To expand on our previous studies, we evaluated the biologic effects of three cysteine analogues in a rodent model of MI. We also found that SPC, SAC, and SPRC displayed cardioprotective effects by reducing infarct size and by reducing LDH and CK leakage from cells (markers of cell-membrane integrity). $\mathrm{H}_{2} \mathrm{~S}$ is a strong reducing agent and may readily react with labile molecules, particularly those derived from reactive oxygen and nitrogen species $(7,23)$. Interestingly, in this study, all three compounds were found to preserve tissue GSH levels and to reduce plasma MDA levels as compared with the MI vehicle group. This observation correlated with 


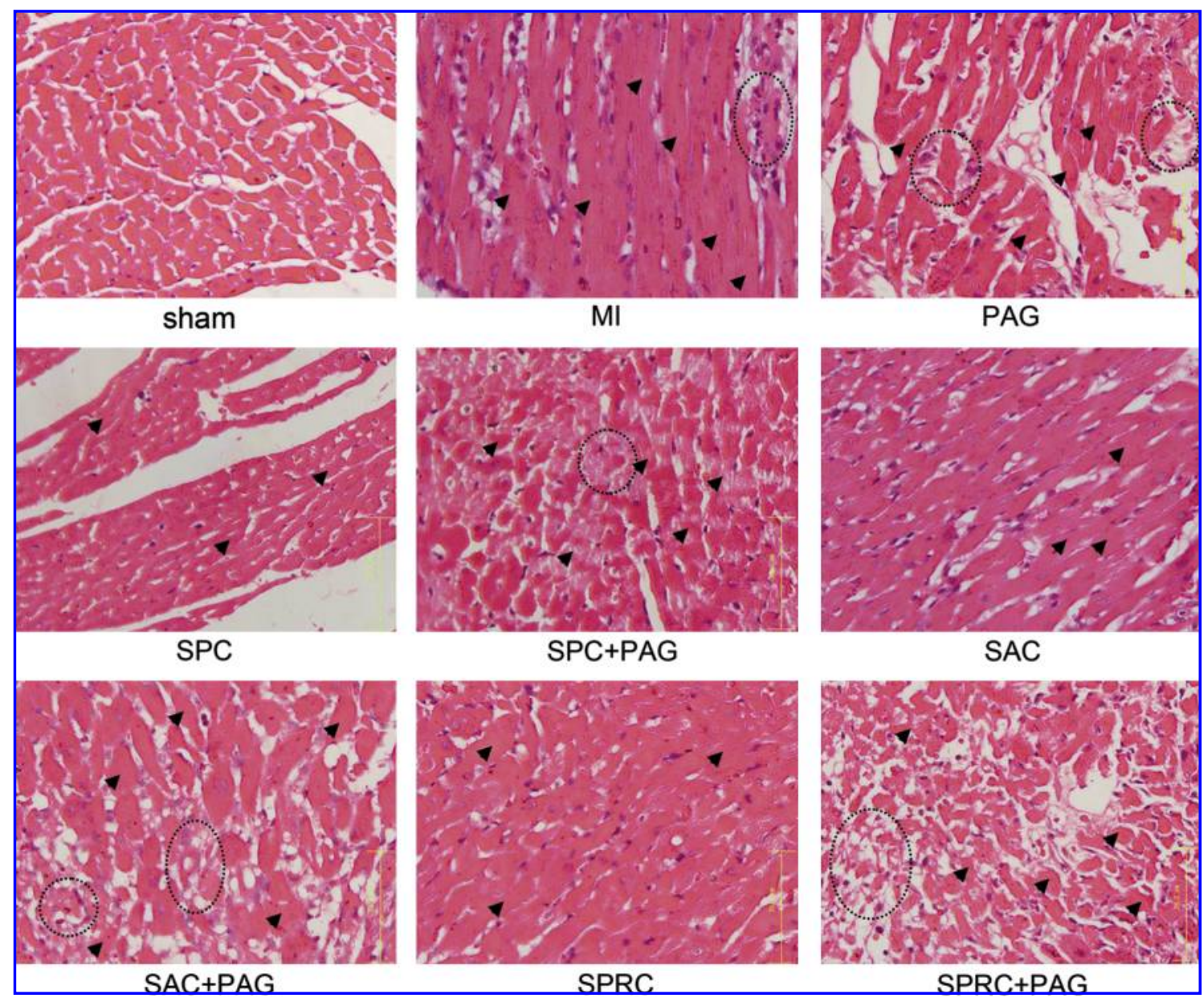

FIG. 7. Pathologic alterations in heart of rats with H\&E staining $(\times \mathbf{4 0 0})$. Myocytes after myocardial infarction: note the nuclear loss in most myocytes and the persistence of nuclear shadows in a few myocytes. $\boldsymbol{\nabla}$ Damaged myocytes; $\bigcirc$ the degenerative muscle fibers. (For interpretation of the references to color in this figure legend, the reader is referred to the web version of this article at www.liebertonline.com/ars).

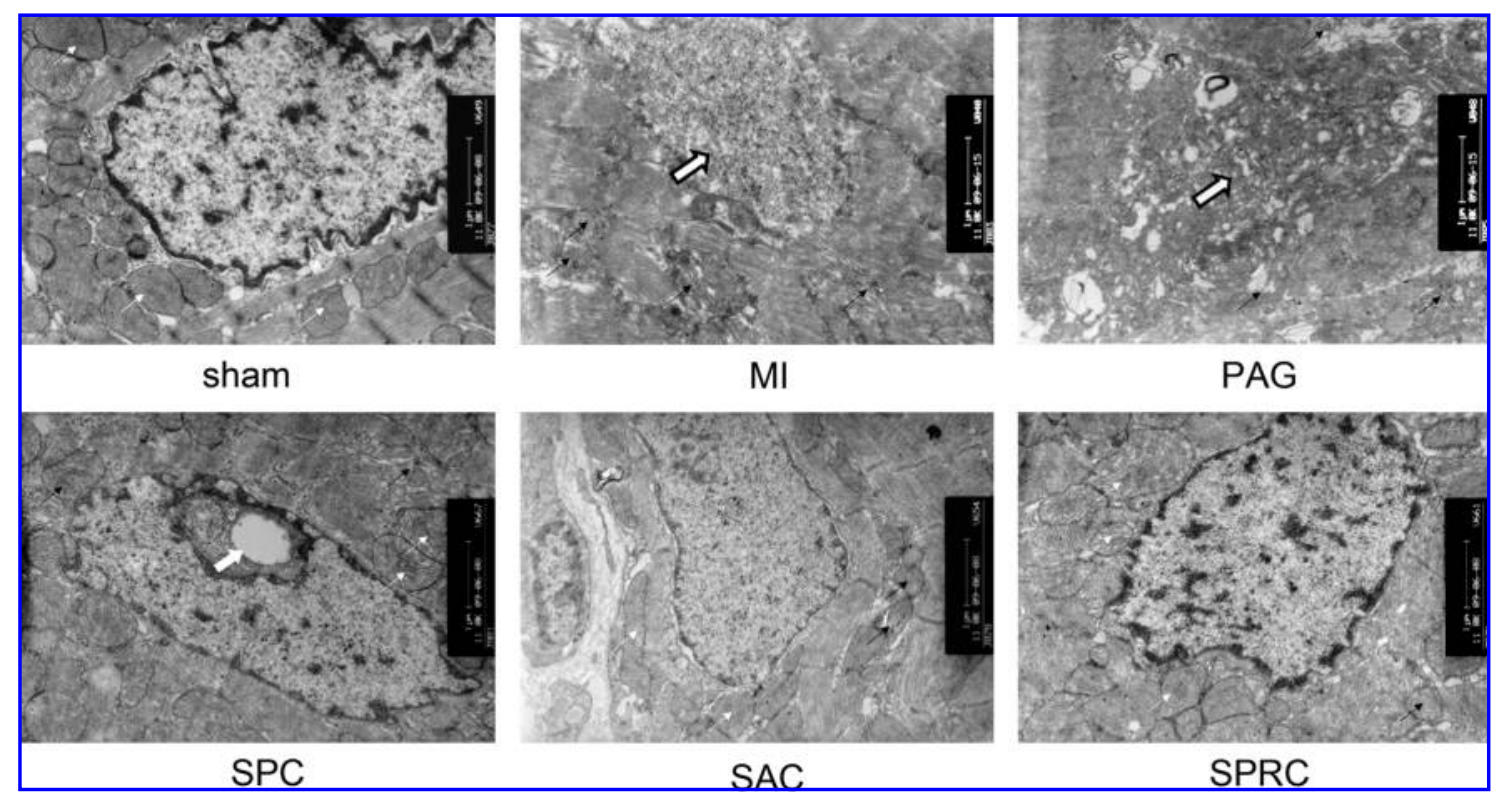

FIG. 8. Ultrastructural changes in hearts of rats after myocardial infarction with electron microscopy $(\times 20,000)$. Wellpreserved nucleus with finely dispersed chromatin with a prominent nucleolus was shown in the sham group. $\nearrow$ (white) showed normal mitochondrial; $\nearrow$ (black) indicated swelling mitochondria and some mitochondria with ruptured outer membrane; $\uparrow$ the abnormal nuclei with fragments; $\uparrow$ (white) the bubble in the nucleus in the SPC-treated group. 
a committed upregulation of the enzyme CSE and with the induction of the cardioprotective enzymes SOD and GPx in myocardial tissues. Banerjee and colleagues (3) previously reported that rats fed with raw garlic homogenates showed a significant preservation of myocardial superoxide dismutase (SOD) activity and an improvement in myocardial morphology after MI induction with isoproterenol. In our study, we found that SPC preserved the activity of cytosolic copper/zinc SOD (CuZn-SOD); the predominant SOD in mammals. SPRC improved manganese SOD (Mn-SOD) activities, and SAC was found to increase both $\mathrm{Cu}-\mathrm{Zn}$ SOD and Mn-SOD activities in MI tissues. In addition, each compound was found to maintain tissue GSH levels after the induction in MI. These findings correlate with a reduction in the levels of MI injury. With the use of immunofluorescence assays, we can see the positive correlation of expression of CSE and Mn-SOD (Fig. 3). It suggested the production of endogenous $\mathrm{H}_{2} \mathrm{~S}$ might increase the protein expression of the antioxidant enzyme Mn-SOD. SPRC involved the $\mathrm{CSE} / \mathrm{H}_{2} \mathrm{~S}$ pathway may be a means of activating Mn-SOD.

In a separate set of experiments, we also evaluated whether the cysteine analogues used in the current study activated the Akt signaling pathway. Akt is a serine/threonine kinase, and a number of studies have reported that the activity of this protein can be regulated through redox stress (20). The Akt protein, once activated, can phosphorylate a wide range of intracellular substrates that regulate growth, metabolism, and survival (5). The Akt pathway is activated not only by various growth factors and cytokines but also by $\mathrm{G}$ protein-coupled receptor agonists, such as bradykinin, through transactivation of receptor tyrosine kinase or activation of nonreceptor tyrosine kinase, such as Src, in a ROS-dependent manner (17). In our study, we found increased expression of phospho-Akt in these cysteine-containing compounds-treated groups. But the SPRC-treated group had the more significant Akt-signaling pathway. PAG may abolish this redox-sensitive signaling in all PAG-intervention groups.

In conclusion, we report that the novel cysteine analogues SPC, SAC, and SPRC enhance cellular antioxidant defenses in rats with MI. SPRC might have a higher selection for CSE. We hypothesize that SPRC perhaps acts as an $\mathrm{H}_{2} \mathrm{~S}$ donor and that the $\mathrm{H}_{2} \mathrm{~S}$ released might participate in activating signaling cascades associated with the prevention of oxidative stress in MI. Collectively, the ability of the $\mathrm{CSE} / \mathrm{H}_{2} \mathrm{~S}$ pathway to alter the oxidative condition suggests that the modulation of CSE expression and $\mathrm{H}_{2} \mathrm{~S}$ production may provide a novel therapeutic avenue for the treatment of ischemic cardiac diseases.

\section{Contribution of the Authors}

Q. Wang is the main person who conducted the study; X.L. Wang and H.R. Liu assisted in the experiments. P. Rose was involved in scientific discussion of the study, and Y.Z. Zhu is the PI for this project.

\section{Acknowledgments}

The current study was supported mainly by research grants from the National Natural Science Foundation of China (grant 30772565), National 973 project (grants 2007CB512006 and 2010CB12600), Shanghai-Unilever Research \& Development Fund (08540750400), National Natural Science Funds for Distinguished Young Scholar (30888002), and Fudan postgraduate innovation fund (EYF129001).

\section{Author Disclosure Statement}

No competing financial interests exist.

\section{References}

1. Ali MY, Ping CY, Mok YY, Ling L, Whiteman M, and Bhatia $\mathrm{M}$. Regulation of vascular nitric oxide in vitro and in vivo: a new role for endogenous hydrogen sulfide. $\mathrm{Br} J$ Pharmacol 149: 625-634, 2006.

2. Alvarez MC, Caldiz C, Fantinelli JC, Garciarena CD, Console GM, Chiappe de Cingolani GE, and Mosca SM. Is cardiac hypertrophy in spontaneously hypertensive rats the cause or the consequence of oxidative stress? Hypertens Res 31: 1465-1476, 2008.

3. Banerjee SK and Maulik SK. Effect of garlic on cardiovascular disorders: a review. Nutr I 1: 4, 2002.

4. Borek C. Garlic reduces dementia and heart-disease risk. J Nutr 136(3 suppl): 810S-812S, 2006.

5. DeBosch B, Treskov I, Lupu TS, Weinheimer C, Kovacs A, Courtois M, and Muslin AJ. Akt1 is required for physiological cardiac growth. Circulation 113: 2097-2104, 2006.

6. Dieterich S, Bieligk U, Beulich K, Hasenfuss G, and Prestle J. Gene expression of antioxidative enzymes in the human heart: increased expression of catalase in the end-stage failing heart. Circulation 101: 33-39, 2000.

7. Geng B, Chang L, Pan CS, Qi YF, Zhao J, and Pang YZ. Endogenous hydrogen sulfide regulation of myocardial injury induced by isoproterenol. Biochem Biophys Res Commun 318: 756-763, 2004.

8. Han SY, Hu Y, Anno T, and Yanagita T. S-propyl cysteine reduces the secretion of apolipoprotein B100 and triacylglycerol by hepG2 cells. Nutrition 18: 505-509, 2002.

9. Kimura $\mathrm{Y}$ and Kimura $\mathrm{H}$. Hydrogen sulfide protects neurons from oxidative stress. FASEB J 18: 1165-1176, 2004.

10. Krest I, Glodek J, and Keusgen M. Cysteine sulfoxides and alliinase activity of some allium species. L Agric Food Chem 48: 3753-3760, 2000.

11. Liu L and Yeh YY. Water-soluble organosulfur compounds of garlic inhibit fatty acid and triglyceride syntheses in cultured rat hepatocytes. Lipids 36: 395-400, 2001.

12. LoPresti R, Catania A, and D'Amico T. Oxidative stress in young subjects with acute myocardial infarction: evaluation at the initial stage and after 12 months. Clin Appl Thromb Hemostasis 14: 421-427, 2008.

13. Maurice J, Lucien L, Gabriel M, and Pierre M. L-Cysteine derivatives for arteriosclerosis treatment. Ger Offen 1974: 18 pp. Patent, German.

14. Mukherjee S, Banerjee SK, Maulik M, Dinda AK, Talwar KK, and Maulik SK. Protection against acute Adriamycininduced cardiotoxicity by garlic: role of endogenous antioxidants and inhibition of TNF-alpha expression. BMC Pharmacol 3: 16, 2003

15. Nagini S. Cancer chemoprevention by garlic and its organosulfur compounds: panacea or promise? Anticancer Agents Med Chem 8: 313-321, 2008.

16. Ola-Mudathir KF, Suru SM, Fafunso MA, Obioha UE, and Faremi TY. HProtective roles of onion and garlic extracts on cadmium-induced changes in sperm characteristics and testicular oxidative damage in rats.H TFood Chem ToxicolT 46: 3604-3611, 2008.

17. Otani H. Reactive oxygen species as mediators of signal transduction in ischemic preconditioning. Antioxid Redox Signal 6: 449-469, 2004. 
18. Senthil S, Veerappan RM, Ramakrishna Rao M, and Pugalendi KV. HOxidative stress and antioxidants in patients with cardiogenic shock complicating acute myocardial infarction. HClin Chim Acta 348: 131-137, 2004.

19. Tsuge $K$, Kataoka M, and Seto Y. Determination of $S$-methyl-, $S$-propyl-, and $S$-propenyl-L-cysteine sulfoxides by gas chromatography-mass spectrometry after tert-butyldimethylsilylation. IAgric Food Chem 50: 4445-4451, 2002.

20. Valko M, Leibfritz D, Moncol J, Cronin MTD, Manzur M, and Telser J. Free radicalsand antioxidants in normal physiological functions and human disease. Int I Biochem Cell Biol 39: 44-84, 2007.

21. Wang Q, Liu HR, Mu Q, Rose P, and Zhu YZ. S-Propargylcysteine protects both adult rat hearts and neonatal cardiomyocytes from ischemia/hypoxia injury: the contribution of the hydrogen sulfide-mediated pathway. I Cardiovasc Pharmacol 54: 139-146, 2009.

22. Wei HL, Zhang CY, Jin HF, Tang CS, and Du JB. Hydrogen sulfide regulates lung tissue oxidized glutathione and total antioxidant capacity in hypoxic pulmonary hypertensive rats. Acta Pharmacol Sin 29: 670-676, 2008.

23. Yan SK, Chang TJ, Wang H, Wu LY, Wang R, and Meng $\mathrm{QH}$. Effects of hydrogen sulfide on homocysteine-induced oxidative stress in vascular smooth muscle cells. Biochem Biophys Res Commun 351: 485-491, 2006.

24. Zhang S, Du J, Jin H, Li W, Liang Y, Geng B, Li S, Zhang C, and Tang C. Endogenous sulfur dioxide aggravates myocardial injury in isolated rat heart with ischemia and reperfusion. Transplantation 87: 517-524, 2009.

25. Zhao WM and Wang $\mathrm{R} . \mathrm{H}_{2} \mathrm{~S}$-induced vasorelaxation and underlying cellular and molecular mechanisms. Am J Physiol Heart Circ Physiol 283: H474-H480, 2002.

26. Zhu YZ, Huang SH, Whiteman M, Tan B, Sun J, and Zhu YC. Antioxidants in Chinese herbal medicines: a biochemical perspective. Nat Prod Rep 21: 478-489, 2004.

27. Zhu YZ, Wang ZJ, Ho P, Loke YY, Zhu YC, Huang SH, Tan CS, Whiteman M, Lu J, and Moore PK. Hydrogen sulfide and its cardioprotective effects in myocardial ischemia in experimental rats. LAppl Physiol 102: 261-268, 2007.

Address correspondence to: Prof. Yi-Zhun Zhu 826 Zhang Heng Road

Shanghai, 201203

China

E-mail: zhuyz@fudan.edu.cn

Date of first submission to ARS Central, October 12, 2009; date of acceptance, October 19, 2009.

$\begin{aligned} & \quad \text { Abbreviations Used } \\ \mathrm{AMI} & =\text { acute myocardial infarction } \\ \mathrm{CAT} & =\text { catalase } \\ \mathrm{CK} & =\text { creatine kinase } \\ \mathrm{CSE} & =\text { cystathionine- } \gamma \text {-lyase } \\ \mathrm{GPX} & =\text { glutathione peroxidase } \\ \mathrm{GSH} & =\text { reduced glutathione } \\ \mathrm{GSSG} & =\text { oxidized glutathione } \\ \mathrm{H}_{2} \mathrm{~S} & =\text { hydrogen sulfide } \\ \mathrm{LCA} & =\text { left anterior descending coronary artery } \\ \mathrm{LDH} & =\text { lactate dehydrogenase } \\ \mathrm{MDA} & =\text { malonaldehyde } \\ \mathrm{Mn}-\mathrm{SOD} & =\text { manganese SOD } \\ \mathrm{PAG} & =\text { DL-propargylglycine } \\ \mathrm{SAC} & =S \text {-allyl-L-cysteine } \\ \mathrm{SOD} & =\text { superoxide dismutase } \\ \mathrm{SPC} & =S \text {-propyl-L-cysteine } \\ \mathrm{SPRC} & =S \text {-propargyl-L-cysteine } \\ \mathrm{TTC} & =2,3,5 \text {-triphenyltetrazolium chloride }\end{aligned}$



This article has been cited by:

1. Rui Wang . 2010. Hydrogen Sulfide: The Third Gasotransmitter in Biology and MedicineHydrogen Sulfide: The Third Gasotransmitter in Biology and Medicine. Antioxidants \& Redox Signaling 12:9, 1061-1064. [Abstract] [Full Text] [PDF] [PDF Plus] 